\title{
Acoustic properties of Composite Coir Mats
}

\author{
Shiney $\mathrm{A}^{(1)}$, Premlet $\mathrm{B}^{(2)}$ \\ ${ }^{1}$ Karpagam university, Coimbatore,TN,India \\ ${ }^{2}$ TKM College of Engineering,Kerala,India
}

\begin{abstract}
In this paper we report the acoustic characterization of coir mats - a biofibremat of various weaving patterns. Being non-hazardous and fully eco friendly with fairly good sound absorption, coir mats are suitable material for acoustic applications for building and automobiles. The study reveals the potential use of coir mats for acoustic absorption purposes. Coir mats of three different weaving were selected for the study viz.Panama, Herringbone and Boucle weaving pattern.The experiment is performed on an impedance tube apparatus as per ASTM E 1050/ISO 10534-2.The effect of latex backing and thickness on absorption coefficient are also studied. The experimental analysis is made for the frequency range $100 \mathrm{~Hz}-6300 \mathrm{~Hz}$.The results reveals that the mats shows good absorption coefficient at high frequencies and also the mats with latex backing and increased thickness improves the absorption of coir mats.Coating mats with fire resistant material makes it suitable for building acoustics and automobiles.
\end{abstract}

Keywords: coir mats,panama weave,Herringbone weave,Boucle weave,Absorption coefficient, NRC, boimats, biofibre

\section{Introduction}

Along with advances in technology, noise has become a serious environmental problem. Noise can cause general types of negative effects which include hearing loss,auditory health effect,individual behaviour,effect on sleep,communication interference and effect on domestic animals and wild life. Noise control is one of the major requirements to improve the living environment.There are several methods to decrease noise,one of which uses sound absorption materials. Sound Absorption coefficient(SAC) is defined as the fraction of randomly incident sound energy which is absorbed by the surface.

Currently,sound absorption materials commercially available for acoustic treatment consist of glass or mineral-fiber materials. However,when reviewing the issue of safety and health,these fibers when exposed to humans can interfere with human health mainly lungs and eyes. These issues explore an opportunity to look for alternative materials from organic fibers to be developed as sound absorption materials.

Organic fibers as basis for absorber materials have several benefits:renewable,nonabrasive,cheaper,abundant and less potential health risks and safety concerns during handling and processing.Agriculture waste of coconut fiber,rice husk and oil palm may be used as substitutes for wood based raw materials.

Several research were carried out to study the potential use of coir in replacing synthetic and mineral based fibers for sound absorption applications. It is reported that porous layer backing and perforated plate on coir fiber can improve noise absorption coefficient at low and high frequencies[1]. The absorption of coir fiber can be enhanced by compressing the material.Some studies examined the sound coefficient of coconut coir fiber for the purpose of substituting the conventionally used materials such as glasswool and rockwool[2].They reported that the coconut coir fiber has high potential to be utilized as sound absorbing materials.Davern [3]reported that the the porosity of the perforated plate and density of the porous material would significantly affect the acoustic impedance and sound absorption coefficient of the panel,and the frequency band near the resonance frequency achieve high acoustic absorption.Lee an Chen[4] found that the acoustic absorption of multilayer materials is better with a perforated plate backed with airspaces. Several researchers[5-6] have succeeded in developing particle composite boards using agricultural wastes.

Coir mats are extracted from a coconut byproduct and used to create natural aesthetically appealing doorway mats. Coir is a dyeable material that comes available in a wide array of fibre sizes and mat heights. Coir Mats are made on handlooms, power looms or frames and with or without brush. It is available in a range of colours, sizes and designs. The brushing qualities of coir doormats and their ability to keep the dirt away make the product a unique one. Mats are available in plain, natural and bleached, available with woven or stencilled designs and bevelled patterns for use in interior or exterior door fronts. These mats offer a host of benefits including durability, weather resistance and easy maintenance.

Coir Matting is primarily used as a floor furnishing material. It is widely used in exhibition and fairs as a temporary but neat and elegant floor coverings. Because of its sound deadening characteristics, it is being used 
on a large scale for furnishing stairs, corridors, and auditorium and cinema halls. A wide range of attractive designs and colours as well as quality makes it a favourite item for interior decorators.

So far many research revealed the effectiveness of coir fiber in sound absorption, the use of coir mats as an acoustic material is rarely studied.This paper mainly aims at the study of acoustic absorption coefficient and various acoustic parameters of coir mats having different pattern of weaving.

\section{Test Material And Experimental Test Procedure}

Coir mats of different weaving pattern are available.Mats with panama weaving,Herringbone weaving and Boucle weaving with and without latex backing are selected for the study.Sound absorption coefficient ,Noise reduction coefficient(NRC), and the effect of thickness in absorption coefficient are also studied.

The test procedure is done using impedance tube apparatus as per ASTM E 1050/ISO 10534-2 [7]

\section{Test Procedure}

- The normal incidence sound absorption coefficient (NISAC) measurement was carried out on coir mat samples using impedance tube as per ISO 10534-2 / ASTM E- 1050.

- Multichannel data acquisition system PULSE,Type 3560D,B\&K Denmark make

- Power Amplifier,Type 2716,B\&K Denmark make

- $\quad 1 / 4$ " Microphones,G.R.A.S.,Denmark make

- The samples were cut of $45 \mathrm{~mm}$ and $100 \mathrm{~mm}$ diameter using die cutter. The impedance tube of different diameters were used to evaluate the sound absorption from $100 \mathrm{~Hz}-6300 \mathrm{~Hz}$ at one third octave frequency band.

- During testing the coir mat was facing the source side. Also measured the sound absorption facing latex side to see the effect of latex on sound absorption.

- The Noise Reduction Coefficient (NRC) is calculated for each sample. NRC is single number value, which is average of sound absorption coefficient at $250 \mathrm{~Hz}, 500 \mathrm{~Hz}, 1000 \mathrm{~Hz}$ and $2000 \mathrm{~Hz}$.

- The sound absorption measurements were carried out at room temperature $26^{\circ} \mathrm{C}+/-1^{\circ} \mathrm{C}$ and humidity 49 $+/-1 \%$.

\section{Result And Discussion}

Normal incidence sound absorption coefficient values of sample 1and 2

\begin{tabular}{|l|l|l|l|}
\hline $\begin{array}{l}\text { Onethird octave } \\
\text { frequency,Hz }\end{array}$ & $\begin{array}{l}\text { Sample1-2+2 panama-1750 } \\
\text { GSM and 7.5mm thick }\end{array}$ & $\begin{array}{l}\text { Sample2-2+2 panama with } \\
\text { latex backing-1950 GSM and } \\
8.7 \text { mm thick }\end{array}$ & $\begin{array}{l}\text { Sample2-2+2 panama with latex } \\
\text { backing 1950 GSM and 8.7mm } \\
\text { thick with latex side facing source }\end{array}$ \\
\hline 100 & 0.05 & 0.06 & 0.02 \\
\hline 125 & 0.05 & 0.06 & 0.02 \\
\hline 160 & 0.06 & 0.05 & 0.04 \\
\hline 200 & 0.07 & 0.04 & 0.05 \\
\hline 250 & 0.07 & 0.05 & 0.06 \\
\hline 315 & 0.09 & 0.07 & 0.08 \\
\hline 400 & 0.09 & 0.09 & 0.08 \\
\hline 500 & 0.08 & 0.08 & 0.08 \\
\hline 630 & 0.08 & 0.09 & 0.08 \\
\hline 800 & 0.07 & 0.08 & 0.08 \\
\hline 1000 & 0.08 & 0.09 & 0.10 \\
\hline 1250 & 0.11 & 0.12 & 0.14 \\
\hline 1600 & 0.15 & 0.17 & 0.20 \\
\hline 2000 & 0.18 & 0.21 & 0.26 \\
\hline 2500 & 0.21 & 0.27 & 0.35 \\
\hline 3150 & 0.32 & 0.41 & 0.53 \\
\hline 4000 & 0.51 & 0.64 & 0.78 \\
\hline 5000 & 0.83 & 0.91 & 0.92 \\
\hline 6300 & 0.80 & 0.93 & 0.99 \\
\hline NRC & $\mathbf{0 . 1 0}$ & $\mathbf{0 . 1 1}$ & $\mathbf{0 . 1 2}$ \\
\hline
\end{tabular}




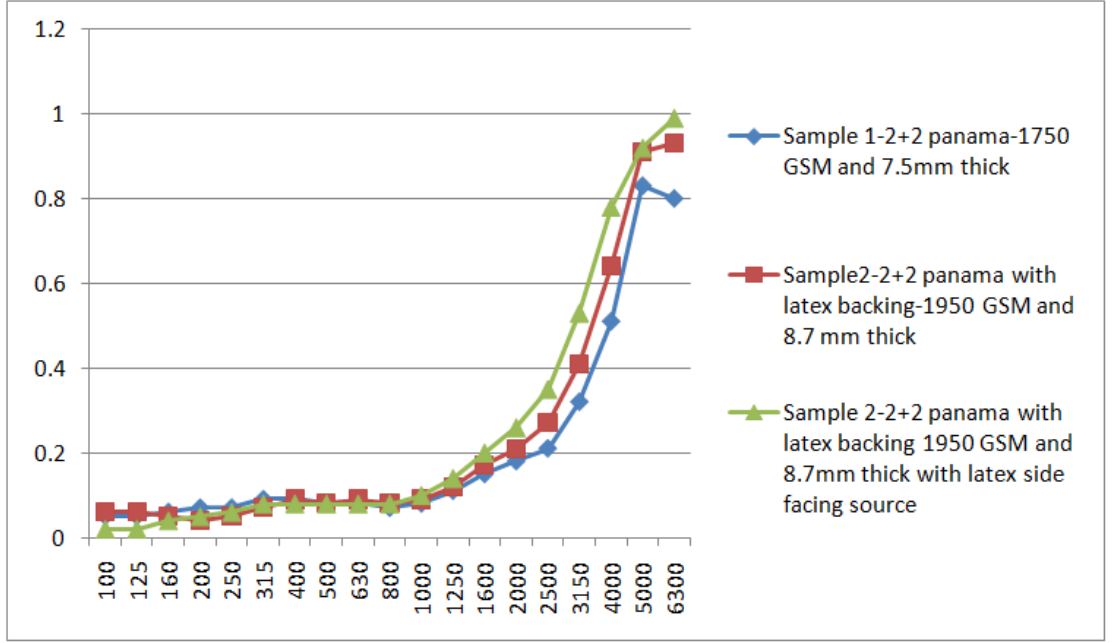

$\mathrm{X}$-axis-Frequency in Hertz

Y-axis-Normal incidence sound absorption coefficient

Sounnd absorption coefficient of Samples I\&II for frequencies $100 \mathrm{~Hz}-6300 \mathrm{~Hz}$ is measured. Samples I and II show less sound absorption upto to $2000 \mathrm{~Hz}$. This is due to low sample thickness(8-10mm) and low flow resistivity.Above $2000 \mathrm{~Hz}$ the sound absorption increases. The NRC values of the samples are $0.10,0.11,0.12$ respectively. This shows that the NRC increases when the latex side faces the source.

Normal incidence sound absorption coefficient values of sample 3 and 4

\begin{tabular}{|c|c|c|c|}
\hline $\begin{array}{l}\text { One third octave } \\
\text { frequency, } \mathrm{Hz}\end{array}$ & $\begin{array}{l}\text { Sample3 -Herringbone matting- } \\
1800 \text { GSM and } 8.6 \mathrm{~mm} \text { thick }\end{array}$ & $\begin{array}{l}\text { Sample4-Herringbone matting } \\
\text { with latex backing } 2150 \text { GSM } \\
\text { and } 9 \mathrm{~mm} \text { thick }\end{array}$ & $\begin{array}{l}\text { Sample4-Herringbone } \\
\text { matting with latex } \\
\text { backing,latex facing source- } \\
2150 \text { GSM and } 9 \mathrm{~mm} \text { thick }\end{array}$ \\
\hline 100 & 0.05 & 0.04 & 0.04 \\
\hline 125 & 0.05 & 0.05 & 0.05 \\
\hline 160 & 0.07 & 0.06 & 0.07 \\
\hline 200 & 0.07 & 0.07 & 0.09 \\
\hline 250 & 0.08 & 0.08 & 0.08 \\
\hline 315 & 0.09 & 0.09 & 0.08 \\
\hline 400 & 0.09 & 0.09 & 0.08 \\
\hline 500 & 0.08 & 0.08 & 0.09 \\
\hline 630 & 0.08 & 0.08 & 0.09 \\
\hline 800 & 0.07 & 0.08 & 0.10 \\
\hline 1000 & 0.09 & 0.10 & 0.11 \\
\hline 1250 & 0.12 & 0.12 & 0.13 \\
\hline 1600 & 0.15 & 0.17 & 0.18 \\
\hline 2000 & 0.18 & 0.20 & 0.23 \\
\hline 2500 & 0.21 & 0.23 & 0.30 \\
\hline 3150 & 0.31 & 0.35 & 0.46 \\
\hline 4000 & 0.49 & 0.53 & 0.66 \\
\hline 5000 & 0.58 & 0.77 & 0.80 \\
\hline 6300 & 0.76 & 0.92 & 0.98 \\
\hline NRC & 0.10 & 0.11 & 0.13 \\
\hline
\end{tabular}




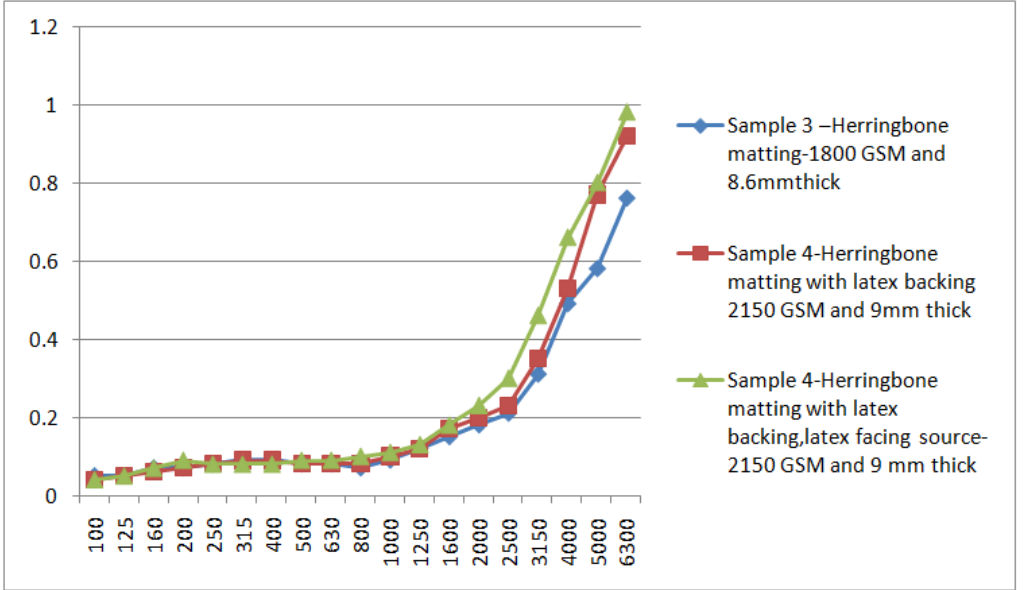

X-axis-Frequency in Hertz

Y-axis-Normal incidence sound absorption coefficient

The results shows that samples $3 \& 4$ shows that absorption coefficient increases above $2000 \mathrm{~Hz}$ and the latex backing improves the SAC and it is further increased when latex side faces the source.NRC values are $0.10,0.11,0.13$ respectively.NRC of the mat when latex side facing the source good result than others.

Normal incidence sound absorption coefficient values of sample 5and 6

\begin{tabular}{|l|l|l|l|}
\hline $\begin{array}{l}\text { One third } \\
\text { octave } \\
\text { frequency,Hz }\end{array}$ & $\begin{array}{l}\text { Sample 5 -2+1 boucle with sisal tight with latex } \\
\text { backing-2750 GSM and 8mm thick }\end{array}$ & $\begin{array}{l}\text { Sample 5-2+1 Boucle with sisal } \\
\text { tight with latex backing-2750 } \\
\text { GSM and 8mm thick with latex } \\
\text { side facing source }\end{array}$ & $\begin{array}{l}\text { Sample 6- 2+1 } \\
\text { boucle 2500 GSM } \\
\text { and 12 mm thick }\end{array}$ \\
\hline 100 & 0.02 & 0.02 & 0.02 \\
\hline 125 & 0.02 & 0.03 & 0.04 \\
\hline 160 & 0.04 & 0.04 & 0.04 \\
\hline 200 & 0.04 & 0.05 & 0.03 \\
\hline 250 & 0.05 & 0.05 & 0.04 \\
\hline 315 & 0.06 & 0.07 & 0.07 \\
\hline 400 & 0.07 & 0.08 & 0.06 \\
\hline 500 & 0.06 & 0.07 & 0.07 \\
\hline 630 & 0.06 & 0.08 & 0.07 \\
\hline 800 & 0.07 & 0.09 & 0.09 \\
\hline 1000 & 0.09 & 0.13 & 0.12 \\
\hline 1250 & 0.13 & 0.19 & 0.14 \\
\hline 1600 & 0.18 & 0.30 & 0.19 \\
\hline 2000 & 0.24 & 0.42 & 0.23 \\
\hline 2500 & 0.31 & 0.59 & 0.27 \\
\hline 3150 & 0.49 & 0.81 & 0.41 \\
\hline 4000 & 0.74 & 0.95 & 0.60 \\
\hline 5000 & 0.89 & 0.96 & 0.73 \\
\hline 6300 & 0.88 & 0.97 & 0.92 \\
\hline NRC & $\mathbf{0 . 1 1}$ & $\mathbf{0 . 1 7}$ & $\mathbf{0 . 1 2}$ \\
\hline
\end{tabular}




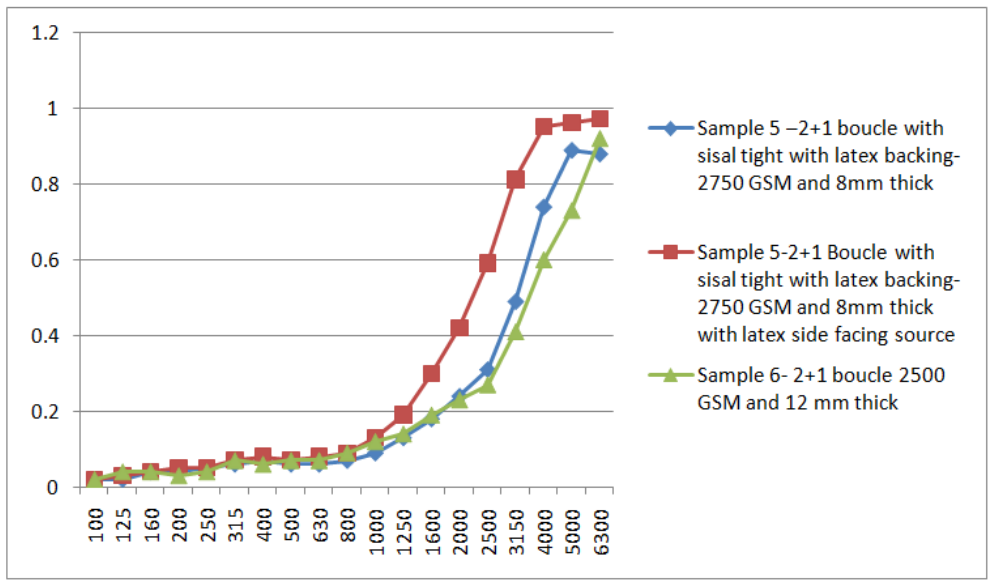

$\mathrm{X}$-axis-Frequency in Hertz

Y-axis-Normal incidence sound absorption coefficient

The SAC of Boucle weaved mat is better at high frequencies. The sample shows good absorption when latex side faces the source.NRC of this sample is appreciable.

SAC of sample-1 for different thickness-7.5mm,16mmand $32 \mathrm{~mm}$.

\begin{tabular}{|l|l|l|l|}
\hline $\begin{array}{l}\text { One third octave } \\
\text { frequency,Hz }\end{array}$ & $\begin{array}{l}\text { Sample1-2+2 panama-1750 } \\
\text { GSM 7.5mm thick }\end{array}$ & $\begin{array}{l}\text { Sample1-2+2 panama-1750 GSM and } \\
\text { 16mm thick }\end{array}$ & $\begin{array}{l}\text { Sample1-2+2 panama- } \\
\text { 1750 GSM and 32mm } \\
\text { thick }\end{array}$ \\
\hline 100 & 0.05 & 0.10 & 0.18 \\
\hline 125 & 0.05 & 0.11 & 0.19 \\
\hline 160 & 0.06 & 0.12 & 0.19 \\
\hline 200 & 0.07 & 0.14 & 0.19 \\
\hline 250 & 0.07 & 0.12 & 0.20 \\
\hline 315 & 0.09 & 0.13 & 0.21 \\
\hline 400 & 0.09 & 0.15 & 0.22 \\
\hline 500 & 0.08 & 0.18 & 0.25 \\
\hline 630 & 0.08 & 0.19 & 0.27 \\
\hline 800 & 0.07 & 0.16 & 0.33 \\
\hline 1000 & 0.08 & 0.17 & 0.44 \\
\hline 1250 & 0.11 & 0.20 & 0.62 \\
\hline 1600 & 0.15 & 0.27 & 0.82 \\
\hline 2000 & 0.18 & 0.36 & 0.86 \\
\hline 2500 & 0.21 & 0.49 & 0.80 \\
\hline 3150 & 0.32 & 0.69 & 0.79 \\
\hline 4000 & 0.51 & 0.77 & 0.78 \\
\hline 5000 & 0.83 & 0.72 & 0.81 \\
\hline 6300 & 0.80 & 0.74 & 0.83 \\
\hline NRC & $\mathbf{0 . 1 0}$ & $\mathbf{0 . 2 1}$ & $\mathbf{0 . 4 4}$ \\
\hline
\end{tabular}

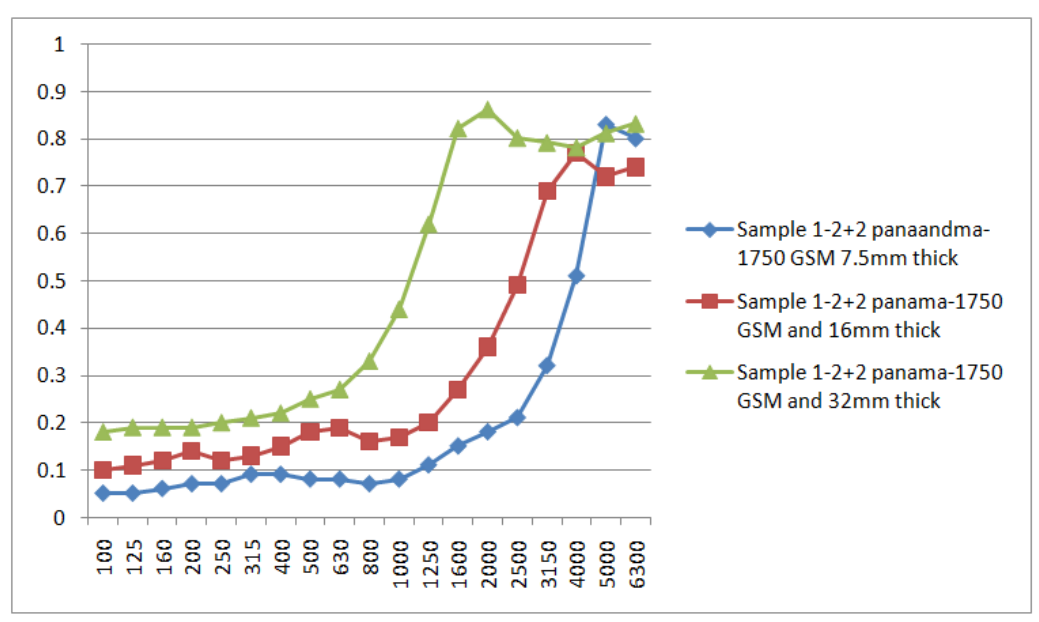

.X-axis-Frequency in Hertz 
Y-axis-Normal incidence sound absorption coefficient

When the thickness of the sample is increased,the absorption coefficient also increases.

\section{Conclusion}

Coir mats shows high absorption above $2000 \mathrm{~Hz}$.All the mats show good absorption when they are given latex backing.SAC also shows good results when the latex side faces the source.NRC of the samples shows that Boucle weaved mat with sisal tight shows NRC of 0.17 when the latex side faces the source.For panama weaved mat,as sample thickness is increased its SAC and NRC increases.Coir mats with latex backing and a suitable coating with fire resistant material are suitable sound absorptive material for building acoustics and automobiles. The study of the modifications on surface features of coir mats to improve the NRC could be an extension to the current research.

\section{References}

[1]. Rozli Zulkifli, et al science publications,sciences,7(2):260-264,2010 ISSN 1546-9239

[2]. Mohd J.M.Nor,et al American journal of Applied sciences,volume7, issue9,page 1285-1290

[3]. Davern,W.A..,Applied Acous 10,85-112(1997)

[4]. $\quad$ Lee,F-C..and W.H..Chen,j sound vib 4,621 (2001)

[5]. Baranek,L.L and I.L.Ver,'Noise Absorption and Vibration Control Engineering:Principles and Applications',2 ${ }^{\text {nd }}$ Edn(WileyInterscience,Newyork,1992

[6]. Delany,M.E. and E.N.Bazley,Applied Acoust.3(1970) 105-116

[7]. ASTM E 1050-98-Standard Test Method for Impedance and Absorption of Acoustical materials using a Tube,Two Microphones and a Digital Frequency Analysis System.(1998) 